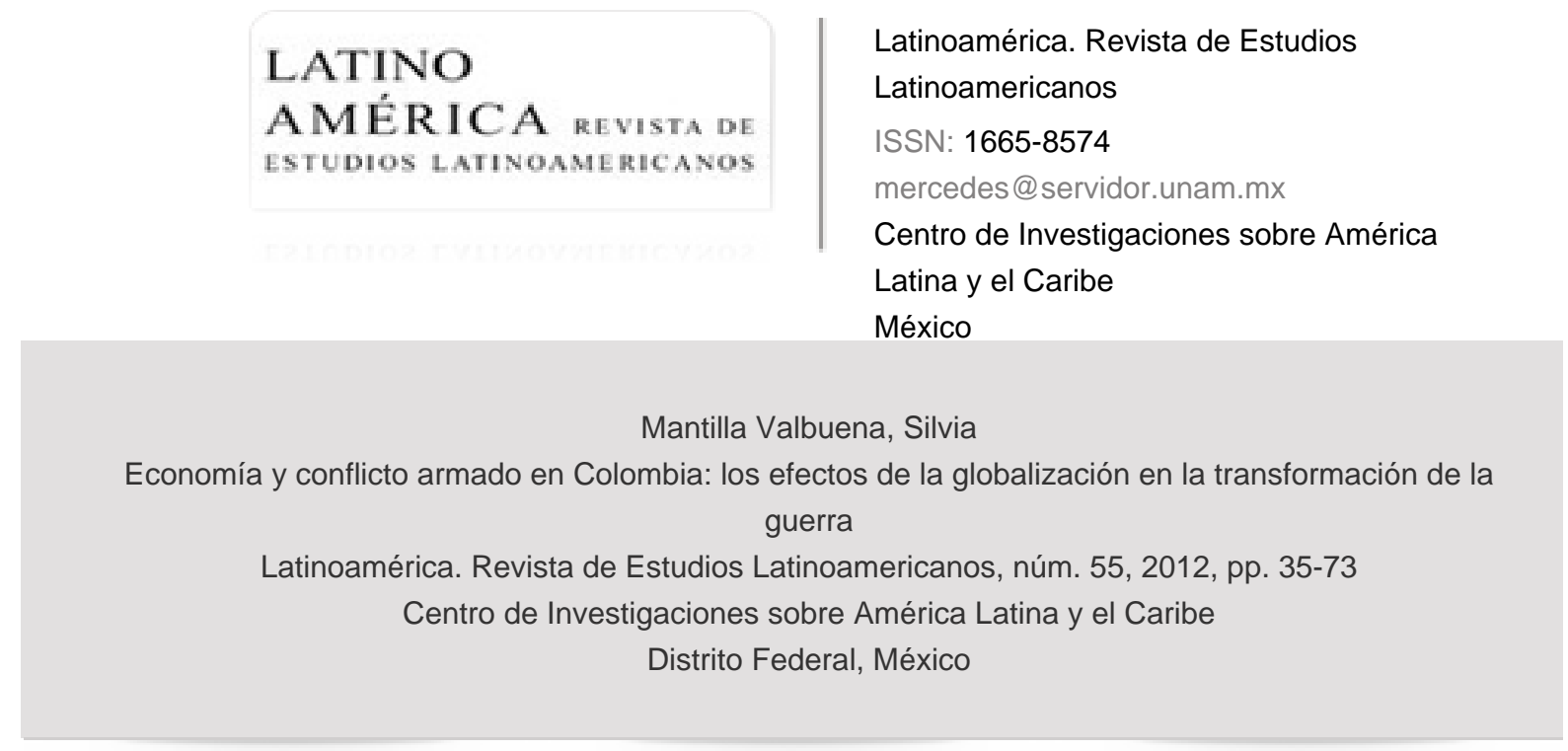

Disponible en: http://www.redalyc.org/articulo.oa?id=64024698003

Cómo citar el artículo

- Número completo

- Más información del artículo

- Página de la revista en redalyc.org

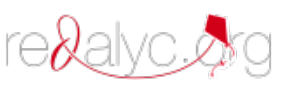

Sistema de Información Científica

Red de Revistas Científicas de América Latina, el Caribe, España y Portugal Proyecto académico sin fines de lucro, desarrollado bajo la iniciativa de acceso abierto 


\section{Economía y conflicto armado en Colombia: los efectos de la globalización en la transformación de la guerra}

\section{Silvia Mantilla Valbuena*}

Resumen: El conflicto armado colombiano ha sufrido en las dos últimas décadas, un proceso de transformación que se encuentra íntimamente ligado a los efectos y dinámicas económicas producidas por el fenómeno de la globalizacion.' Esto ha sido posible fundamentalmente por dos razones: 1. Por el impacto del modelo de apertura económica que reconfiguró al Estado nación colombiano, propiciando el surgimiento de nuevos factores asociados al conflicto; y 2. Por las nuevas oportunidades que la globalización le ofreció a los actores armados para desarrollar su economía de guerra, a través de las economías ilegales de carácter global y de los repertorios globales de la seguridad internacional.

PalabRas clave: Globalización, Neoliberalismo, Conflicto armado, Narcotráfico, Economía de guerra.

ABSTRACT: The armed conflict in Colombia has suffered, in the past two decades, a transformation process closely linked to the economic effects and dynamics produced by the globalization phenomenon. This has been made possible mainly by two aspects: 1 . The impact of the free market model, which reconfigured the Colombian state and gave in for the emergence of new factors associated with the conflict, and 2. The opportunities provided by globalization for armed actors to develop their own war economy through illegal global economies and global repertoires of international security.

Key words: Globalization, Neoliberalism, Armed conflict, Drug-traffic, War economy.

Universidad Nacional de Colombia, sede Caribe (scmantillav@unal.edu.co).

1 Se dice que el fenómeno de la globalización en su sentido histórico ha estado presente desde el momento mismo en que las potencias europeas - España, Portugal e Inglaterra - se aventuraron a la búsqueda de nuevos territorios e iniciaron un proceso de expansión alrededor del mundo, marcado por la progresiva articulación de un sistema mundial de relaciones comer- 


\section{INTRODUCCIÓN}

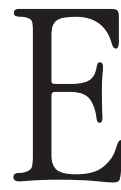

ste artículo pretende proponer diversos argumentos que nos ayuden a determinar por qué la nación colombiana pasó de tener un conflicto armado interno, avivado por las luchas campesinas y socialistas de los años sesenta, a lidiar con la guerra internacionalizada, degradada y prolongada que persiste en la actualidad. Para ello partimos del supuesto de que el grado explicativo de los factores internacionales en la evolución del conflicto ha adquirido un peso significativo y que la dimensión económica del reciente fenómeno de la globalización, así como los cambios estructurales que ella ha generado en el Estado colombiano, son una variable poderosa para explicar la prolongación, agudización e intratabilidad de la confrontación armada.

A continuación se plantean dos rutas de análisis. La primera de ellas, vincula la llegada del fenómeno de la globalización con la implementación del modelo de apertura neoliberal ${ }^{2}$ en Colombia. Para esto se propone el desarrollo de la siguiente hipótesis: la llegada de la globalización y la implementación de las medidas neoliberales posibilitaron la recomposición y el auge del conflicto en tres sentidos específicos: 1. Debido al cambio de orientación en el sector productivo del país en relación con las nuevas dinámicas de las economía internacional; 2. Debido a la profundización del problema de la productividad y el acceso a la

ciales, económicas y culturales. En este artículo nos referimos específicamente a la última "ola de la globalización" o globalización o de la "sociedad pos-industrial", que se refiere al momento histórico de finales del siglo xx — década de los setenta— en que empiezan a gestarse procesos acelerados de revolución tecnológica, económica e informativa a escala global. Véase, Alvin Toffler, La tercera ola, Barcelona, Plaza y Janés, 1980 y Samuel Huntington, La tercera ola: la democratización a finales del siglo, Buenos Aires, Paidós, 1994. Autores que hacen referencia a algunos de estos procesos, en sus libros.

2 El neoliberalismo se constituyó en el modelo de desarrollo propio de la globalización; por tanto, la evaluación de su impacto en la reconfiguración del conflicto armado en Colombia debe pasar, de manera inevitable, por el debate acerca de los efectos producidos por la implementación del modelo neoliberal. Si bien se podría realizar un estudio extenso sobre los factores asociados al modelo de desarrollo y su impacto en distintas esferas de la vida nacional, nos interesa aquí centrarnos en los aspectos que han producido un efecto específico sobre las condiciones del conflicto armado. 
tierra; y 3. Por el efecto económico que produjo la descentralización político administrativa.

Una segunda hipótesis plantea que el conflicto colombiano se agudizó y se prolongó en las dos últimas décadas debido a que el negocio del narcotráfico permeó de manera directa la actividad de los actores insurgentes, y de manera indirecta al actor armado estatal a través de la implementación de las políticas globales de seguridad. Este vínculo entre guerra y narcotráfico sólo fue posible gracias a las oportunidades ofrecidas por el contexto global de las economías ilícitas y de la política de seguridad internacional.

Este texto incluye, pues, una mirada amplia que inicia en la década de los noventa, momento que coincide con la apertura de la economía colombiana y con la adopción sistemática de las políticas neoliberales, y a partir del cual se puede observar también, un escalamiento progresivo en la intensidad del conflicto, hasta su punto más álgido entre los años 1997 y 2003. Se muestran así mismo algunos rasgos de las variaciones o continuidades que ha tenido el conflicto finalizando la década de 2000.

EL NUEVO MODELO DE DESARROLLO ECONÓMICO Y LA RECONFIGURACIÓN DEL ESTADO NACIÓN COMO FACTORES EXPLICATIVOS DE LA TRANSFORMACIÓN DEL CONFLICTO

El autor colombiano Hugo Fazio, entiende la globalización como la expansión del modelo capitalista a escala mundial, basada en el acelerado intercambio de bienes, servicios y mercados que condujo al derrumbamiento de las fronteras nacionales y logró profundizar la interdependencia entre países, regiones, empresas y actores transnacionales que confluyeron en un único sistema de relaciones económicas y de informatización. ${ }^{3}$

3 Hugo Fazio, "La globalización", en Revista La Tadeo, núm. 70, Bogotá, julio-diciembre, 2004, p. 21. 
En Colombia, dicha globalización introdujo diversos cambios estructurales y reconfiguró las relaciones económicas, políticas y sociales del Estado colombiano para permitir el libre desarrollo de la fuerza liberalizante del capitalismo mundial. Las tendencias globalizadoras se materializaron en la suscripción de acuerdos de integración, mercados comunes o zonas de libre comercio, la generalización de estrategias encaminadas a atraer inversión extranjera y la creación de condiciones para suscitar el interés de las grandes empresas transnacionales, así como en el rigor macroeconómico, la preservación de un sano equilibrio fiscal y las políticas de privatización de activos y servicios estatales. ${ }^{4} \mathrm{~A}$ su vez, la globalización exigía una descentralización de las funciones del Estado a fin de hacerlo más eficiente en el manejo de los recursos, así como de fomentar el autosostenimiento de las regiones y localidades del país.

La adopción del neoliberalismo en Colombia se constituyó así en el modelo de desarrollo a través del cual se materializó en buena medida el fenómeno de la globalización, lo que, a su vez, produjo efectos en la problemática del conflicto armado colombiano. A continuación evidenciaremos los aspectos más relevantes de esta transformación.

\section{EL CAMBIO DE ORIENTACIÓN EN EL SECTOR PRODUCTIVO DE COLOMBIA Y SUS VÍNCULOS CON EL CONFLICTO ARMADO}

Colombia pasó de ser un país eminentemente productor de café en la década de los setenta a convertirse en productor de minerales y de coca en la de los noventa. Este cambio en la estructura productiva del país se debió fundamentalmente a los retos que tuvo que enfrentar la economía colombiana de cara a un contexto cada vez más abierto, flexible y competitivo traído por el impulso liberalizador de la globalización.

4 Hugo Fazio, La globalización en su bistoria, Bogotá, Universidad Nacional, 2002, p. 174. 
La participación de la caficultura en el país pasó de representar 50\% de las exportaciones en 1985 a 21\% en 1998 y 8\% en 2000, y su participación en las exportaciones en el contexto mundial que en la década del noventa estaba alrededor del 19\%, para 2005 representaba apenas $14 \% .{ }^{5}$ lo anterior pudo explicarse en primer lugar, en razón de los bajos precios internacionales del grano que empezaron a regir a partir de la década de los ochenta debido a una sobreproducción mundial de café, que fue inducida por el surgimiento de nuevas y viejas economías que aprovecharon el contexto global para expandir su comercialización agrícola. ${ }^{6}$

En segundo lugar, la situación del café en Colombia presentó una condición muy similar a la de buena parte de los productos agrícolas en los países del Tercer Mundo dependientes de las exportaciones, que fueron golpeados duramente por las medidas tanto aperturistas como proteccionistas de los países más poderosos y que fueron desplazados por nuevos productores que aplicaban más tecnología o que ofrecían nuevos productos sustitutos para abastecer la demanda del mercado global.

¿Cómo pudo entonces, este cambio económico y productivo haber afectado y redinamizado la dinámica interna del conflicto armado en Colombia? Se puede decir que hay dos respuestas a esta pregunta, una que puede comprobarse con evidencia teórica y causal, y otra que puede sustraerse de una manera más analítica que directamente verificable.

En cuanto a la primera respuesta, es necesario ubicar el conflicto colombiano en un escenario en que a la par de la crisis agrícola de los países menos desarrollados, la economía internacional comenzó a privilegiar, especialmente en los últimos decenios, el consumo de minerales e hidrocarburos dada la ne-

5 Isaías Tobasura, "La crisis cafetera, una oportunidad para el cambio en las regiones cafeteras de Colombia”, en Revista Agronomía, vol. 13, núm. 2, Bogotá, julio-diciembre, 2005, p. 39.

6 Se sabe, por ejemplo, que la incorporación de avances tecnológicos que llevaron a cabo países como Brasil y Vietnam para hacer crecer su producción de café terminaron por desplazar a Colombia del segundo lugar de producción que había ostentado durante varias décadas. A lo anterior se sumaba un nuevo contexto internacional en que la demanda de café en el nivel mundial disminuía por la aparición de otros productos sustitutos y por los cambios en los gustos de la población joven. 
cesidad cada vez mayor de los países industrializados de obtener insumos industriales y fuentes de energía combustibles derivadas primordialmente del petróleo, ${ }^{7}$ el gas, el carbón, y de algunos minerales como el oro, el níquel y el hierro, entre otros.

Colombia pasó así en los años noventa a consolidarse como un importante productor de minerales y combustibles, en virtud del modelo de producción y de economía que empezó a prevalecer con la demanda de estos recursos en el ámbito mundial. El petróleo, el carbón y el oro se posicionaron como los productos cuya producción y crecimiento se mantuvieron en ascenso desde la década de los noventa mostrando el potencial minero y energético que tenía el país (véase gráfico 1), en un contexto internacional en que los precios del crudo y demás minerales se habían mantenido altos y relativamente constantes.

\section{Gráfico 1}

Valor de la producción del sector minero sin hidrocarburos y participación en el PIB

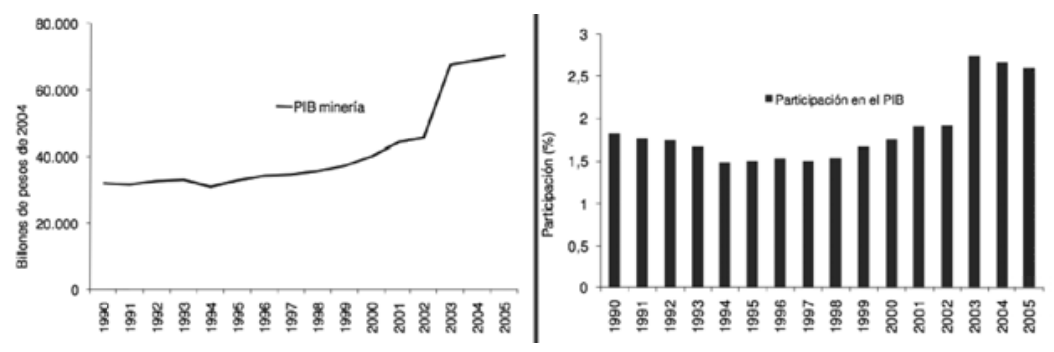

FuENTE: Departamento Administrativo Nacional de Estadística. La minería en Colombia: impacto socioeconómico y fiscal, Bogotá, Fedesarrollo, abril, 2008.

7 Durante el año 2004, el consumo mundial de petróleo se elevó 3.4\% y alcanzó los 82.4 millones de barriles al día. Los responsables de casi la mitad del aumento son Estados Unidos y China, que en la actualidad utilizan 20.5 y 6.6 millones de barriles diarios, respectivamente. Véase el Informe Vital Sign, Instituto Worldwatch, 2005. En http://www.worldwatch.org/bookstore/publication/vital-signs-2005. 
El petróleo, específicamente, se convirtió en el principal renglón de exportaciones del país y en una importante fuente de ingresos para el Estado. Durante la década de los noventa, por ejemplo, el sector petrolero aumentó su participación en el Producto Interno Bruto (PIB) de 1.5\% en 1994 a 3.6\% en $1999^{8}$ y su producción creció de 126 mil bpd (barriles por día) en 1980 a 816 mil bpd en 1999, ${ }^{9}$ posicionando al país como uno de los principales productores de crudo del continente latinoamericano, después de México, Brasil y Venezuela. Si bien no puede decirse que Colombia haya sido una potencia petrolera en el nivel regional, en las últimas décadas, con la política minera de Álvaro Uribe que se consolidó posteriormente con la "locomotora minero energética"10 del actual gobierno de Juan Manuel Santos, Colombia se ha situado entre los primeros 20 productores mineros en el ámbito mundial. ${ }^{11} \mathrm{~A}$ través de esta "locomotora", se ha fomentado una exploración y explotación agresiva de las fuentes de crudo, impulsada en buena medida por las facilidades que el Estado le ha otorgado a la inversión extranjera, lo cual llevó al país a la histórica cifra de 965 mil bpd a finales del año 2011. ${ }^{12}$

Esta nueva orientación del sector productivo vinculada a la economía internacional, se constituyó en un nuevo escenario que fue aprovechado por los actores armados: Fuerzas Armadas Revolucionarias de Colombia (FARC), ${ }^{13}$ Ejér-

8 Janet Rodríguez, "Petróleo para Dummies", en Carta Petrolera, ed. 118, Bogotá, febrero, 2008. En http://www.ecopetrol.com.co/especiales/cartapetrolera118/rev_empresa.htm.

9 Agencia Nacional de Hidrocarburos, "Sector colombiano del petróleo y el gas", Caribbean Round, 2007. En http://www.anh.gov.co/ronda2007.anh.gov.co/internae8ec.html?id=91.

${ }^{10}$ El plan de desarrollo del actual presidente de Colombia Juan Manuel Santos definió cinco ejes programáticos o "Locomotoras de crecimiento": infraestructura, vivienda, agro, minería e innovación. La locomotora de la minería es la que más conflictos presenta por cuanto genera problemáticas ambientales, sociales y ambientales de gran envergadura para el país.

11 Democracia en la red. Resistiendo al despojo de la locomotora minero energética, 15 de abril, 2012. En http://democraciaenlared.wordpress.com/2012/04/15/resistiendo-al-despojo-de-la-locomo-tora-minero-energetica/.

12 "Colombia produjo 965.000 barriles diario petróleo en noviembre", en Revista Semana, $1^{\circ}$ de diciembre, 2001. En http://www.semana.com/economia/colombia-produjo-965000-barriles-diario-petroleo-noviembre/168462-3.aspx.

${ }^{13}$ La FARC son un grupo guerrillero de origen campesino que surgió en la década de los sesenta con una ideología marxista y que tenía como objetivo derrocar a las clases políticas tradicionales 
cito de Liberación Nacional (ELN) ${ }^{14}$ y Autodefensas Unidas de Colombia o grupos paramilitares (AUC), ${ }^{15}$ que se fueron expandiendo hacia nuevas zonas de riquezas ubicadas en los centros urbanos y semiurbanos del país, con el fin de dinamizar su economía de guerra a través de formas tanto directas como indirectas de explotación de los recursos altamente rentables en el mercado internacional.

El ejemplo más claro de dicha relación entre recursos mineros y conflicto, se ha evidenciado a lo largo de dos décadas después de haberse descubierto en 1983 uno de los campos petroleros más grandes y productivos denominado Caño Limón, ${ }^{16}$ ubicado en la región de Arauca, departamento de Casanare. Es importante anotar que en esta región ya existía previamente la presencia de las fuerzas del Ejército de Liberación Nacional y del Frente Décimo de las FarC que se habían establecido allí hacia 1982.

Los grandes beneficios que suponían la explotación del petróleo en la zona, abrieron de este modo una ventana de oportunidad para que estos grupos pudie-

con el fin de ejercer el control directo de las fuerzas del Estado. Si bien ha existido un progresivo desvanecimiento del ideal de construir un Estado marxista, lo cierto es que las FaRC aún hoy se mantienen en conflicto por las políticas que rigen la explotación de los recursos naturales y la inequitativa distribución de tierras, que para ellos significa el principal factor que define el desarrollo económico del país.

${ }^{14}$ El ELn nace en 1964 en la región del Magdalena Medio santandereano y se define en sus inicios como un grupo de orientación marxista leninista y pro castrista que posteriormente fue influenciado por la denominada Teología de la Liberación Nacional. Estos componentes ideológicos llevaron a este grupo a establecer una estrategia de poder popular mucho más sólida que la de cualquier otro actor insurgente, a través de la búsqueda de un capital político fundado en procesos de movilización y organización social, más que en la estrategia militar o de saqueo de recursos.

${ }^{15}$ Los paramilitares se vincularon desde su aparición a principios de la década de los ochenta con los grandes carteles del narcotráfico. El tipo de coalición que dio origen a este grupo armado fue fundamentalmente una coalición entre ganaderos, militares y narcotraficantes, que surgió como respuesta al hostigamiento de las guerrillas en el campo, y fue también una coalición alentada por algunas políticas promulgadas por el mismo gobierno estatal. Los paramilitares han incrementado significativamente su participación y control del negocio de las drogas en las últimas décadas.

${ }^{16}$ El oleoducto mide $780 \mathrm{kms}$ de longitud y transporta a diario unos 80 mil barriles de crudo que se producen en los campos de Caño Limón, operados por la estadounidense Occidental y ubicada en el departamento de Arauca, en la frontera con Venezuela, hasta el puerto de Coveñas, en el mar Caribe, para su exportación. 
ran financiar su economía de guerra, basados en un discurso nacionalista que pretendía proteger a la región y al país de los efectos perversos que las multinacionales producían sobre las economías productoras de petróleo. La relación entre los grupos armados y este recurso es descrita por Jenny Pearce en un estudio de campo sobre el fracaso de la política estatal y la militarización multipolar en el Casanare,

[...] Oil predation was therefore linked to its political objectives around oil policy and this continued to be the case in the 1990s. Economically it was able to make money from Occidental through kidnapping oil workers, attacks on oil installations and extortion of contract companies and repair firms. Guerrillas were to blow up the pipeline 911 times between 1986 and 2001.The guerrillas claimed to be representing the interests of the Sarare communities in forcing the oil company to pay for social programmes in the area $[\ldots]$. The farc was responsible for a marked escalation of attacks on the oil pipeline from 2000 to 2001; there were 266 attacks in those years, compared to 645 in the previous 15 years. ${ }^{17}$

La depredación se ha mantenido como una constante en la última década, lo cual se refleja en el hecho de que en el pasado año 2011 se contabilizaron 84 ataques contra oleoductos y carros tanques y en 2012 se incrementaron los atentados contra el oleoducto de Caño Limón Coveñas y los secuestros contra el personal del sector. ${ }^{18}$

Otro de los casos representativos ha sido el del control y el pago forzoso de cuotas por parte de los distintos actores armados a la producción de oro, especialmente en las zonas auríferas del sur de Bolívar, Antioquia y Nariño. ${ }^{19} \mathrm{Co}-$

${ }^{17}$ La autora Jenny Pearce anota sin embargo, que las guerrillas pudieron ganar un punto de apoyo para la depredación del petróleo debido al poder social y armado con el que estos grupos ya contaban luego de haber construido su autoridad política y militar en la región de Arauca desde la década de los ochenta. Jenny Pearce, "Policy Failure and Petroleum Predation: The Economics of Civil War Debate Viewed 'From the War-Zone"', en Government and Opposition, vol. 4, núm. 2, 2005, Oxford, Blackwell Publishing, p. 169.

18 “iEn dónde está el Petróleo?”, en Revista Semana, 23 de junio, 2012. En http://www.semana.com/ economia/donde-esta-petroleo/179414-3.aspx.

19 Véase Otto Vergara, "Conflicto y ordenamiento territorial en regiones con potencial minero en Colombia", en Dimensiones territoriales de la guerra y la paz, Bogotá, Universidad Nacional de Colombia, 2004 (Red de Estudios de Espacio y Territorio). Ralf Leiteriz, Carlo Nasi y Angelika Rettberg, "Para desvincular los recursos naturales del conflicto armado en Colombia", en Revista Colombia Internacional, núm. 70, julio-diciembre, 2009. 
lombia es un país con gran potencial de producción de minerales preciosos, entre los cuales, el oro y las esmeraldas ocupan ahora un papel central. Si bien la producción de estos minerales no es nueva, pues el país los ha exportado desde la época de la colonia, fue a partir de la década de los ochenta, cuando comenzó a evidenciarse la verdadera viabilidad económica y comercial de este recurso en el ámbito nacional e internacional.

La producción de oro ha pasado, sin embargo, por diversas fases de crecimiento y declinación desde la década de los noventa. Así, su valor de producción que durante 1994 fue de 232 mil millones de pesos, comenzó un proceso de disminución permanente hasta 1998 cuando su magnitud fue sólo de 120 mil millones. Más adelante, entre 1994 y 1996 la producción de oro pasó de 20.76 a 22.07 toneladas, para caer levemente durante 1997 a 18.81 toneladas y mantenerse en ese valor en 1998. En 1999 las cifras indican un aumento en la producción a 33.88 toneladas con un incremento del 80\% y durante el año 2000 estas cifras muestran una producción de 37.01 toneladas con un incremento de $9.24 \%{ }^{20}$

Entre los años 2004 y 2010 se sigue presentando un crecimiento relativamente estable de la producción de oro por gramos — excepto en los años 2006 y 2007-, como muestra el gráfico 2.

\section{Gráfico 2}

Colombia. Producción de oro 2004-2010 en gramos

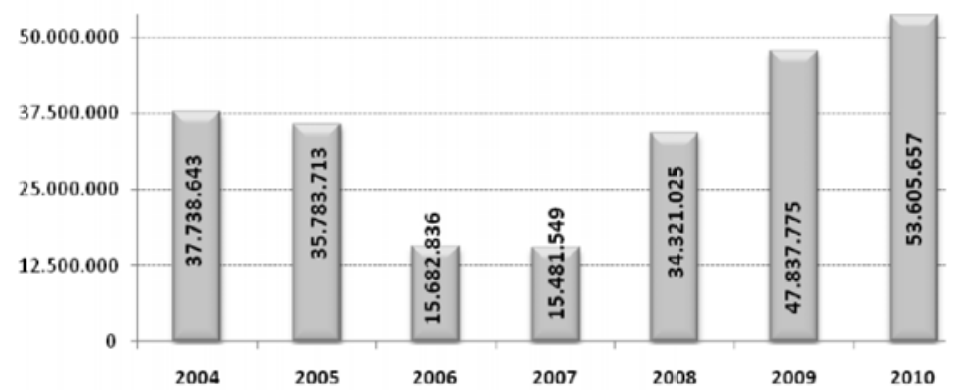

FUENTE: Ingeominas, "Comportamiento de la producción de minerales y de las regalías mineras en Colombia", Ministerio de Minas y Energía, 2010-2011. En http://www.simco.gov.co/LinkClick. aspx?fileticket $=$ PNRNmYEjMVo\%3D\&tabid $=128$.

${ }^{20}$ Datos tomados de Vergara, op.cit., p. 404. 
Vale la pena señalar en torno a las fluctuaciones de la producción de este recurso, como sugiere la Fundación para la Educación Superior y el Desarrollo de Colombia (Fedesarrollo), que el oro tiene unas características únicas que hacen que el comportamiento de su precio internacional sea atípico, pues se trata de un bien que sirve como cobertura frente a la inflación. En ese sentido, el auge de su demanda se debe más a los temores inflacionarios que han dominado la escena internacional y no tanto al consumo excesivo de los agentes económicos que lo usan como insumo. ${ }^{21}$ Las últimas décadas han mostrado, no obstante, un crecimiento sostenido del precio internacional del oro así como de su consumo, lo que ha incentivado su explotación y producción en diferentes regiones del mundo. ${ }^{22}$

La producción de oro en el país ha sido representativa, aunque no exclusiva, de la región del Magdalena Medio que une al sur de Bolívar con la región central del departamento de Antioquia. Este negocio ha estado en buena parte mediado por la lógica del contrabando y ha tendido a caracterizarse por la escasa presencia o la ausencia total del Estado.

Desde la década de los ochenta cuando la producción se hace significativa en la región del Magdalena Medio antioqueño y bolivarense, ocurre un fuerte movimiento poblacional atraído por las expectativas económicas y comerciales alrededor de la explotación de este recurso. A partir de ese momento comenzaron a producirse una serie de conflictos sociales y económicos que se vieron agravados con la irrupción violenta de grupos armados de guerrillas, paramili-

${ }^{21}$ La joyería industrial se constituye también en uno de los principales consumidores mundiales donde el consumo de joyas utiliza el oro como una forma de ahorro e inversión o precaución contra la inflación y otros imprevistos. Además el oro tiene distintos usos que están vinculados a las industrias internacionales, tales como la industria aeroespacial donde éste actúa como un protector a la radiación, la industria arquitectónica en los grandes edificios para que se reduzca el calor producido por los rayos infrarrojos del sol, en la medicina para la artritis, los tratamientos de cáncer, así como en la industria electrónica, en donde se usa para los circuitos de calculadoras, los set de televisión, las computadoras y los teléfonos etc. Fedesarrollo, La minería en Colombia: impacto socioeconómico y fiscal, Bogotá, abril de 2008.

${ }^{22}$ Entre los principales productores mundiales de oro se encuentran en orden de importancia, China, Australia, Estados Unidos, Sudáfrica, Rusia, Perú, Indonesia, Canadá, Ghana, México y Colombia entre otros. 
tares y ejército que iniciaron una cruenta lucha por el control de estos territorios. El eln por ejemplo, ya tenía presencia en esta zona con el Frente Camilo Torres, razón por la que tradicionalmente se consideró al sur de Bolívar, especialmente en los municipios de Simití y San Pablo, como una de sus zonas estratégicas de influencia; en estos municipios comenzaron a operar poco después los frentes XXIV y XIVI de las FARC, así como en otros municipios del norte de la región como Río Viejo, Morales, Barranco, Arenal y Archí, donde también habían operado los frentes xxIv, xxxvi y José Sepúlveda de las FARC.

A partir de la década de los noventa inicia la arremetida de los paramilitares en la región del Magdalena Medio y el Sur de Bolívar, donde este grupo armado se hizo del control de la minería artesanal aurífera. Ello trajo como resultado una crisis social y humanitaria reflejada en 36 mil personas desplazadas entre 1997 y 2009, 700 desapariciones documentadas entre 1999 y 2000, y 380 asesinatos entre 1997 y 2007 en la zona del Sur de Bolívar. ${ }^{23}$ En la década de 2000, el paramilitarismo y las nuevas Bandas Criminales (Bacrim) terminaron finalmente por masacrar a un sinnúmero de líderes miembros de las organizaciones mineras que fueron asesinados, desaparecidos y estigmatizados con el transcurso de los años.

La actividad que desarrollaron los distintos grupos armados en torno a este recurso ha sido, como en el caso del petróleo, una política de saqueo y depredación tanto directa como indirecta que ha tenido como fin la obtención de ganancias económicas y el control del territorio y de la población,

[...] en esta región y en otras comunidades sustentadas en la producción del oro, incluida la región del bajo cauca antioqueño, los grupos armados cobran por dragas y motobombas de los medianos y pequeños mineros; han fijado el pago de un impuesto a los productores de oro; imponen contribuciones al comercio y ejercen estricto control en negocios como bares y cantinas, restaurantes, hoteles; poseen y administran sus propias minas, supervisan a las compañías de

23 Para ampliar la información sobre la relación entre minería y violencia en Colombia, véase "ColomPBIa. Minería en Colombia ¿A qué precio?", en Boletín Informativo, núm 18, noviembre de 2011. En http://www.pbi-colombia.org/fileadmin/user_files/projects/colombia/files/colomPBIa/ 111122_boletin_final_web.pdf. 
transporte fluvial y realizan en las administraciones locales lo que podría denominarse una "auditoría social". ${ }^{24}$

Todo lo anterior, se articula directamente con la industria global e internacional en la medida en que un número importante de multinacionales han empezado a invertir y a explotar el recurso en el país, como en los casos de Greystar Resources, con el proyecto aurífero de Angostura en Vetas y California (Santander) y Bullet en Zaragoza (Antioquia). Además de Barrick Gold Corp, Río Tinto Limited, Cambridge Mineral Resources, De Beira Goldfields, Colombia Goldfields y Antofagasta, entre otras.

Finalmente, algunos recursos agrícolas de carácter legal también han desempeñado un papel importante en la relación entre recursos naturales, globalización y conflicto armado en Colombia. Tal es el caso de la plantación extensiva de la palma aceitera, basada en un particular modelo de desarrollo rural que se encuentra directamente vinculado con las prioridades de los mercados internacionales.

Si bien la palma tuvo sus orígenes en Colombia en la década de los treinta y hacia 1945 se inició formalmente su cultivo a través de la United Fruit Company, el verdadero auge del cultivo de palma comenzó a gestarse hacia la década de los noventa, cuando se produce un incremento sostenido de la demanda mundial de grasas y aceites, así como la novedosa posibilidad de utilizar este recurso como biocombustible. Según datos de la Federación Nacional de Cultivadores de Palma de Aceite (Fedepalma), desde los noventa, el crecimiento de la producción anual ha excedido en promedio el incremento del consumo anual de aceites y grasas por cuatro veces, lo cual se ha reflejado en el crecimiento sostenido de las exportaciones. Mientras un 7\% del aceite de palma fue exportado en 1995 , este valor se había incrementado en $25 \%$ en el año 2000, y en 33\% en el año $2006 .{ }^{25}$ Así mismo, el principal mercado de exportación de aceite de palma ha sido la Unión Europea, en donde los países con mayor importancia son Ale-

${ }^{24}$ Vergara, op. cit., p. 414.

${ }^{25}$ Fedepalma, The faces of the oil palm, Bogotá, octubre, 2007. 
mania (39\%) y Reino Unido (17\%), y los mercados principales de exportación de aceite de palmiste por su parte, han sido México (50\%) y Reino Unido (22\%). ${ }^{26}$

En términos de la oferta y producción internacional de este producto, Colombia ocupa entonces un lugar importante, al situarse como el quinto productor y exportador mundial de aceite de palma como puede observarse en la siguiente tabla,

\section{Tabla 1}

Oferta y consumo aparente mundial de aceite de palma en miles de toneladas

\begin{tabular}{|c|c|c|c|c|c|c|}
\hline Pais / County & 2003 & 2004 & 2005 & 2006 & 2007 & $\begin{array}{l}\text { Var. } \\
06 / 07 \% \\
1 \text { Growth rate }\end{array}$ \\
\hline 1. Proclucción / froduction & 28.257 & 30.984 & 33.849 & 37.125 & 38.307 & 3.2 \\
\hline Indonesia & 10.600 & 12.380 & 14.100 & 16.050 & 10.900 & 5.3 \\
\hline Malasia / Mobysa & 13.354 & 13.974 & 14.961 & 15.881 & 15.823 & .0 .4 \\
\hline Tailandia / Thailand & 890 & 735 & 700 & 860 & 1.020 & 18.6 \\
\hline Nigeria & 785 & 790 & 800 & 815 & 835 & 2.5 \\
\hline Colombia* & 527 & 630 & 673 & 710 & 732 & 23 \\
\hline Eeuador & 262 & 279 & 319 & 352 & 396 & 126 \\
\hline Otros / Others & 2.040 & 2.195 & 2.295 & 2.451 & 2.600 & 0.1 \\
\hline II. Importaciones//mports & 21.893 & 23.972 & 26.023 & 29.343 & 29.413 & 0.2 \\
\hline China & 3.353 & 3.851 & 4.320 & 5.402 & 5.499 & 0.7 \\
\hline Unión Europea / European Union & 3.029 & 4.018 & 4.489 & 4.021 & 4.053 & 0.7 \\
\hline India & 3.979 & 3.453 & 3.315 & 3.198 & 3.688 & 15,3 \\
\hline Paquistán / Pakistan & 1.487 & 1.432 & 1.040 & 1.708 & 1.711 & 3.2 \\
\hline Estados Unidos / United States & 200 & 271 & $42 \mathrm{C}$ & 630 & 788 & 25.1 \\
\hline Egipto / Egpt & 878 & 702 & 774 & 770 & 720 & 0.5 \\
\hline Japón / Japan & 428 & $\Delta \infty \infty$ & 479 & 499 & 532 & 0.7 \\
\hline Irân / iman & 280 & 329 & 451 & 367 & 420 & 14.4 \\
\hline Otros / Others & 7.853 & 9.451 & 10.729 & 12.028 & 11.402 & 5.2 \\
\hline III. Exportaciones / Eports & 21.893 & 24.284 & 26.522 & 30.092 & 29.900 & .0 .6 \\
\hline Malasia / Malogsia & 12.216 & 12.582 & 13.439 & 14.423 & 13.747 & .47 \\
\hline Indonesia & 7.370 & 8.996 & 10.436 & 12.540 & 12.050 & 0.9 \\
\hline Papía Nueva Guinea / Papua New Gunea & 327 & 339 & 295 & 302 & 308 & 1,7 \\
\hline Emiratos Arabes / Unied Arao Emirares & 222 & 289 & 208 & 315 & 358 & 13.5 \\
\hline Colombia* & 145 & 244 & 240 & 238 & 341 & 43.5 \\
\hline Otros / Others & 1.613 & 1.834 & 1.845 & 2.214 & 2.440 & 10.2 \\
\hline
\end{tabular}

FuEnTE: Oil World Annual, "Anuario Estadístico", Fedepalma 2008. En http://www.fedepal ma.org/documen/2008/oferta_consumo.pdf.

Dadas las características específicas de este tipo de cultivo y la amplitud de su presencia en el territorio nacional, ${ }^{27}$ se ha producido en los últimos años la

${ }^{26}$ Mónica Hurtado y Giovanni Hernández, "Perfil local y agroindustria palmera: explorando el caso de San Alberto y San Martín (Cesar)", en Cuadernos de Desarrollo Rural, vol. 7, núm. 65, Colombia, 2009, p. 20.

${ }^{27}$ Las plantaciones de palma en territorio nacional han alcanzado las 300000 hectáreas y se ha expandido hacia 16 departamentos y 76 municipios, en el norte, centro, este y oeste del país. 
intervención de los actores armados, especialmente del paramilitarismo, en la búsqueda de formas alternativas de financiación a través de este recurso. De acuerdo con el investigador Sebastián Ocampo, en Colombia se podría observar la relación entre este recurso natural y los actores armados, de dos maneras,

La primera, cuando la producción de palma se vuelve el objeto de las extorsiones que financian grupos armados. En este caso, la palma ya estaba establecida y el conflicto armado llega o se recrudece después. Las extorsiones a los palmicultores, los secuestros de administradores, la obstrucción del transporte de los trabajadores y las amenazas de destrucción de instalaciones de los palmeros por parte de las FaRC en Puerto Wilches (Orrantia 1997) y en San Alberto (Rettberg 2004), y en zona bananera por parte de grupos paramilitares (Goebertus 2008), son muestra de esto. El otro caso, más conocido, consiste en el desplazamiento de familias de sus tierras con la intención de establecer en ellas grandes cultivos de palma de aceite, tal como sucedió con el despojo violento de tierras de las comunidades afrocolombianas que habitan en la cuenca del pacífico chocoano, para dar paso a cultivos de palma. ${ }^{28}$

En los últimos años, la plantación, la explotación y el control del cultivo de la palma ha estado mayoritariamente en manos del poder paramilitar, lo cual ha producido una crisis humanitaria sin precedentes, reflejada en violaciones a los derechos humanos de los líderes de comunidades campesinas e indígenas de las zonas palmeras del Chocó, Santander y Norte de Santander. Las violaciones incluyen masacres, despojos, desplazamientos forzosos de comunidades enteras, con el fin de apoderarse de las tierras aptas para el lucrativo negocio de la palma, todo esto sin contar con la destrucción acelerada de bosques tropicales y ecosistemas biodiversos que supone la explotación del recurso.

Se pueden así enumerar distintos ejemplos en Colombia en los que ocurren situaciones similares alrededor de otros tipos de recursos mineros como el carbón, las esmeraldas y el ferroníquel, que en conjunto soportan la hipótesis de que el cambio de orientación del sector productivo hacia la minería y hacia otros

${ }^{28}$ Sebastián Ocampo, "Agroindustria y conflicto armado. El caso de la palma de aceite", en Revista Colombia Internacional, núm. 70, julio-diciembre, 2009, p. 180. 
recursos agrícolas rentables internacionalmente es el que se ha producido como resultado de las nuevas dinámicas de la economía global, y se ha convertido en una nueva fuente inagotable de recursos económicos para los grupos rebeldes y por esta vía, en un activador potencial de la violencia y del conflicto armado.

Vale la pena advertir que la larga historia de ataques a oleoductos y de extracción de rentas a partir de la economía del oro o de la palma aceitera en Colombia, no reflejan de manera exclusiva una relación depredatoria entre los actores armados y los recursos naturales, sino que en muchos casos es el resultado de un fuerte arraigo político y social de estos grupos en sus comunidades de influencia, lo que hace que las motivaciones económicas se constituyan en una fuente de legitimidad y de financiación para sus propósitos de guerra.

\section{EL PROBLEMA DE LA TIERRA EN VIRTUD DE LAS REFORMAS}

\section{NEOLIBERALES Y DE LA GLOBALIZACIÓN}

Una segunda respuesta sobre cómo la globalización y el neoliberalismo, con el subsecuente cambio en el modelo productivo y de desarrollo del país, pudieron haber redinamizado al conflicto armado interno en Colombia, puede sustraerse de una manera más indirecta que causal.

Si bien no es posible verificar de manera causal si la llegada del neoliberalismo y de la globalización, con el consecuente agravamiento de las condiciones estructurales que ya existían previamente en el campo, condujeron a un crecimiento de los grupos armados y por esta vía a la prolongación y profundización del conflicto, sí podría inferirse, al menos de manera analítica, que las dificultades sociales y económicas, exacerbadas por los efectos del nuevo modelo económico de apertura, propiciaron un contexto en el cual las condiciones de pobreza y desempleo en los territorios rurales pudieron constituirse en motivaciones suficientes para que la mano de obra campesina flotante optara por integrarse a las filas de combatientes de los actores armados o por ser parte de los sistemas productivos de carácter ilegal. 
En primer lugar, la dinámica del conflicto armado, que históricamente y aún hoy es representativa del escenario rural, podía estar mayormente relacionada con las condiciones estructurales y el grave desequilibrio que ha presentado el país entre las ciudades y el campo. Lo anterior implica recordar que el problema de la redistribución de la tierra y de la reforma agraria en Colombia nunca ha podido ser resuelta, al punto en que el coeficiente de Gini de concentración de la tierra se ha mantenido de manera alarmante en alrededor del 0.75 para todo el territorio nacional. ${ }^{29}$

En segundo lugar, si observamos el panorama histórico de las zonas rurales del país, podemos encontrar que las actividades socioeconómicas en el campo han sufrido un declive importante desde la llegada de la apertura económica. A principios de los años setenta, casi la mitad de la población vivía en el campo, la agricultura representaba algo más de $20 \%$ del PIB total, las exportaciones de origen agropecuario constituían 75\% de las exportaciones del país, y un solo producto agrícola, el café, desempeñaba un papel determinante en el comportamiento macroeconómico de la nación..$^{30}$ En las siguientes décadas, como resultado del acelerado y traumático proceso de transformación del sector productivo del país, la agricultura comenzó a presentar un descenso sin precedentes, al punto en que hacia el año 2009 la actividad agropecuaria representaba tan sólo 10\% del PIB total del país. El gráfico número 3 a continuación nos puede dar una idea más amplia de esta evolución,

${ }^{29}$ Héctor Galindo, Jorge Restrepo y Fabio Sánchez, "Conflicto y pobreza en Colombia: un enfoque institucionalista", en Jorge Restrepo y David Aponte [eds.], Guerra y violencias en Colombia. Herramientas e interpretaciones, Bogotá, Pontificia Universidad Javeriana/CEREC, 2009, p. 329.

${ }^{30}$ Juan José Perfetti, Crisis y pobreza rural en Colombia, Centro Latinoamericano para el Desarrollo Rural e Instituto de Estudios Peruanos, núm. 43, noviembre, 2009. En http://www.rimisp.org/FCKeditor/UserFiles/File/documentos/docs/pdf/DTR/N43_2009_Perfetti_crisis-pobre za-rural-caso-Colombia.pdf. 
Gráfico 3

Evolución del sector agropecuario en el campo de Colombia 1970-2005

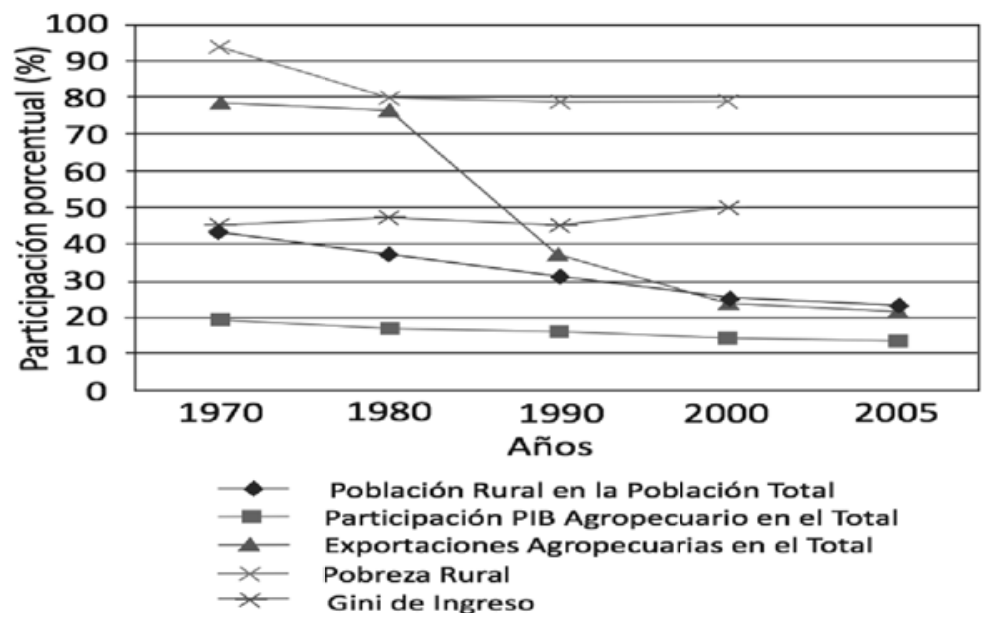

Fuente: Juan José Perfetti, Crisis y pobreza rural en Colombia, Centro Latinoamericano para el Desarrollo Rural e Instituto de Estudios Peruanos, núm. 43, noviembre, 2009.

Se podría inferir de lo anterior, que así como el mantenimiento de un estricto compromiso con la apertura económica, las privatizaciones y la reforma del Estado, prolongaron y profundizaron las disparidades socioeconómicas entre los distintos grupos sociales al interior del país, ${ }^{31}$ dichas reformas profundizaron también las disparidades entre las unidades territoriales, a saber, la ciudad y el campo. Este desequilibrio se masificó claramente con la desagrarización y el empobrecimiento de las zonas rurales productivas, a tal punto que, según comenta Robledo, ${ }^{32}$ la entrada masiva de toda clase de productos importados devastó a la agricultura colombiana, haciendo que entre 1992 y 1999 los cultivos transito-

${ }^{31}$ Para un análisis más profundo véase Juan José Echeverri, "Colombia en la década de los noventa, neoliberalismo y reformas estructurales en el trópico", en Cuadernos de Economía, vol. 30 , núm. 3, 2000, pp. 121-148.

32 Prácticamente desaparecieron el algodón, el maíz, la cebada, el sorgo, el tabaco y la soya, en tanto disminuyeron el arroz y tantos más. Jorge Enrique Robledo, Neoliberalismo y desastre agropecuario. Ponencia presentada en el Foro "El impacto de la apertura en el sector agro- 
rios disminuyeran en 800 mil hectáreas y que la participación del agro en el Producto Interno Bruto se redujera en casi cuatro puntos. ${ }^{33}$

Si a esto se suma que el cambio de orientación del sector productivo hacia la minería y otros recursos naturales rentables para la economía global han privilegiado un modelo de producción que se caracteriza por ser intensivo en extracción y en adaptación tecnológica pero limitado en el uso de mano de obra, se puede inferir que la situación económica, las condiciones de desempleo y la ausencia de beneficios sociales en el campo disminuyeron de manera efectiva la capacidad de sus pobladores para sostenerse dentro de los límites de la economía legal.

En este sentido, en Colombia se puede observar claramente que, tanto en términos espaciales como temporales, vienen a coincidir en la década de los noventa la situación del estancamiento del empleo en el campo, el exceso de oferta de mano de obra rural y el declive de los cultivos agrícolas tradicionales, con el crecimiento de los grupos armados y de los cultivos ilícitos en el país. ${ }^{34}$ Como argumenta Alejandro Reyes Posada,

La expansión de cultivos de coca y amapola coincidió con un largo periodo de abandono de las economías campesinas y de la quiebra de muchos productores por la apertura de las importaciones subsidiadas del resto del mundo, sumada a

pecuario", organizado por la Asociación Nacional por la Salvación Agropecuaria, Ibagué, 8 de junio, 1999.

33 Según los datos más pesimistas, las políticas aperturistas implementadas en la etapa neoliberal llevaron a incrementar en Colombia en 700\% las importaciones de alimentos, hasta alcanzar cifras cercanas a los 7.5 millones de toneladas anuales. Esto ha acelerado el empobrecimiento del campesinado, que junto a la estrategia violenta y expansionista del latifundio ganadero y narcotraficante es la razón más fuerte para que en Colombia haya más de 2 millones de desplazados forzados. Véase Asociación Campesina del Valle del Río Cimitarra (ACVC), El neoliberalismo, la cuestión agraria y el conflicto social y armado en Colombia, Ponencia presentada por la AcvC en la Conferencia Internacional "El Otro Davos", Magdalena Medio, 19 de enero, 2001. En http://www.prensarural.org/acvc/acvc20010119.htm.

${ }^{34}$ Recordemos que hubo un aumento considerable de áreas de coca cultivadas en Colombia que pasó de 45.000 has en 1994 a 163.000 has en el año 2000. United Nations Office on Drugs and Crime, Colombia Censo de Cultivos de coca, junio de 2005. En http://www.unodc.org/pdf/andean/Colombia_coca_survey_es.pdf. 
la revaluación de la moneda y a la crisis de precios del café, desde comienzos de los noventa..$^{35}$

Se puede concluir entonces a partir de la discusión anterior, que a pesar de las dificultades para establecer una relación causal entre la crisis producida en el campo colombiano como resultado de la apertura neoliberal y el crecimiento de la economía ilícita de los actores armados, al menos analíticamente se puede establecer una correlación lógica que continúa vinculando la situación estructural de las zonas rurales con la prolongación del conflicto como parte de sus condiciones objetivas.

La hipótesis sobre el papel que ha desempeñado una mano de obra flotante y empobrecida de campesinos y pobladores rurales, como base social de los grupos armados y como mano de obra disponible para la economía de la droga no debe ser, por tanto, descartada, pues si bien no puede considerarse como la única razón de la agudización del conflicto en los últimos años, sí se constituye en una más de las condiciones que el contexto de la globalización ha contribuido a profundizar.

\section{LA DESCENTRALIZACIÓN Y EL REFORZAMIENTO}

DE LA CONFLICTIVIDAD EN LAS LOCALIDADES

En Colombia, como en la mayoría de los países latinoamericanos, la globalización vino acompañada de una restructuración económica, política y territorial del Estado nación dirigida a enfrentar las presiones y exigencias económicas del mundo global. En este contexto, la descentralización se constituyó en una de las fórmulas básicas para la salida a los dilemas económicos y sociales propios del

35 Alejandro Reyes, "La cuestión agraria en la guerra y la paz", en Álvaro Camacho y Francisco Leal [comps.], Armar la paz es desarmar la guerra, Bogotá, CEREC/DNO/FESCOL/IEPRI, Misión Social, Presidencia de la República, 2000, p. 216. 
modelo Estado céntrico que predominaba en el sistema regional, ${ }^{36}$ así como para iniciar el proceso de apertura hacia los mercados globales y hacia la democratización.

La orientación de este proceso en la región fue llevada a cabo por las Instituciones Financieras Internacionales, especialmente por instancias como el Fondo Monetario Internacional y el Banco Mundial, que definían los lineamientos de las política económicas a una escala global y condicionaban la entrega de ayudas y créditos, a cambio de que los países latinoamericanos iniciaran un proceso activo de apertura económica, privatización y desconcentración del aparato estatal, como reformas encaminadas a fortalecer las políticas de austeridad y eficiencia en el gasto público.

En Colombia, específicamente, la necesidad que tenía el Estado de disminuir sus responsabilidades como centro regulador de la política social para poder poner en marcha la reforma neoliberal, se manifestó en un profundo proceso de descentralización que inició en la década de los ochenta y se formalizó con la Constitución de 1991 . $^{37}$

A pesar de los avances que esta reforma suponía en términos de la democratización y modernización del Estado, el gobierno central no pudo prever, sin embargo, las consecuencias que este proceso tendría en un país que vivía en medio de un conflicto armado y que, justamente, hacia la década de los noventa

36 Un indicador del cambio es que a comienzos de los años 1980 en 23 de 26 países los alcaldes fueron nombrados por el gobierno central mientras que actualmente (1997) la elección directa de alcaldes es la regla en 17 de los 26 países. Actualmente, en América Latina aproximadamente 13000 gobiernos locales tienen dirigentes electos, contra menos de 3000 al inicio de los años 1980. Otro indicador del cambio es que la participación de gobiernos subnacionales y locales en el gasto total nacional de 14 países latinoamericanos aumentó de 15.6\% en 1985 a 19.3\% en 1995 (promedio ponderado) con una tendencia al incremento de esa participación. Willem Assies, La descentralización en perspectiva, El Colegio de Michoacán y Centro de Estudios Rurales, México, 2003. En http://solidonorte.com/files/el_arte_de_gobernar/ASsiEs\%20Descentralizacion\%20en\% 20perspectiva.pdf.

37 La Constitución de 1991 surgió como un pacto político y social que permitió no sólo incluir a los diferentes grupos étnicos y sociales en los espacios de la participación política, sino delegar responsabilidades políticas y económicas directamente a los mandatarios en los municipios y departamentos. 
experimentaba el despegue económico y territorial de los distintos grupos insurgentes.

En el estudio sobre conflicto, Estado y descentralización en Colombia, los autores Fabio Sánchez y Mario Chacón ${ }^{38}$ comprobaron la hipótesis que relaciona de manera directa la presencia de nuevas riquezas y recursos en los municipios, derivados del proceso de descentralización, y la progresiva expansión, presión y enriquecimiento de los actores armados -FARC-EP, ELN Y AUC - a lo largo y ancho del país. Lo anterior se pudo verificar en virtud del acelerado proceso de transferencias de recursos que se dio desde el Estado central hacia los departamentos y municipios, pues según datos aportados por los mismos autores, durante el periodo 1982-2002, las transferencias totales pasaron de representar 1.9\% del PIB a ser casi $6 \%$ en $2002 .{ }^{39}$

Con la gran cantidad de recursos presupuestales que se trasladaron hacia los gobiernos locales, sobre todo para atender las necesidades de la población en materia de salud, educación y agua potable, se pudo comprobar que los grupos armados se vieron incentivados a obtener un mayor control de los recursos económicos que empezaron a llegar a las localidades, y que ahora se constituían en una fuente clara de poder político y de financiación. Ello se facilitó aún más dado que la descentralización ocurría en un contexto de ausencia histórica de las instituciones de justicia y seguridad del Estado en los territorios alejados del centro, que evidenciaba la debilidad de los municipios y departamentos para ejercer un control territorial capaz de resguardar y proteger tanto los recursos económicos procedentes del gobierno central, como a los miembros o individuos implicados en su manejo.

Una vez que se abrieron nuevas oportunidades económicas y políticas a partir del proceso de descentralización, los actores armados comenzaron entonces a acceder a porciones cada vez mayores de poder por vía de la intimida-

${ }^{38}$ Fabio Sánchez y Mario Chacón, "Conflicto, Estado y descentralización: del progreso social a la disputa armada por el control local 1974-2002", en Francisco Gutiérrez, María Emma Wills y Gonzalo Sánchez [coords.], Nuestra guerra sin nombre. Transformaciones del conflicto en Colombia, Instituto de Estudios Políticos y Relaciones Internacionales (IEPRI), Bogotá, Norma, 2006.

39 Ibid., p. 372. 
ción, de la cooptación o eliminación de los dirigentes regionales, o a través de la apropiación directa de los recursos económicos. Un ejemplo de ello se manifestó en la presión que comenzaron a ejercer los grupos armados en el proceso electoral de los distintos municipios del país, y que reflejó claramente la capacidad que tenían estos grupos para afianzar su control en determinados territorios y utilizar el nuevo engranaje político y económico del Estado a su favor,

La mencionada presión se ha reflejado en la enorme magnitud de la violencia contra candidatos a cargos públicos locales. Según datos de la presidencia de la república, durante el periodo 1998-2001, los grupos armados ilegales asesinaron un total de 70 candidatos a alcaldías, 92 a concejos y 14 a otros tipos de cargos públicos. Siendo 1997 el año más crítico con 57 candidatos asesinados, 100 secuestrados y 369 retirados de la contienda electoral. ${ }^{40}$

Más de dos décadas después de formalizado el proceso de descentralización, la situación de violencia en las localidades se ha mantenido en un nivel alarmante. En las elecciones regionales y locales del mes de octubre de 2011, por ejemplo, se registró una de las campañas más violentas de los últimos años con 41 candidatos políticos asesinados. En un informe de la Misión de Observación Electoral (мов) se determinó que el número de víctimas era superior en $52 \%$ al periodo electoral de 2007, cuando los asesinados sumaron 27, y que aparte de los 41 muertos, hubo 88 candidatos amenazados, 23 atentados y 8 secuestros. ${ }^{41}$ Se informó también que había al menos 978 municipios en riesgo y que la mayor parte de esta cooptación violenta de los poderes locales se debía a la expansión y el fortalecimiento de los reductos paramilitares y/o nuevas bandas criminales a lo largo y ancho del país. ${ }^{42}$

En definitiva, la transferencia masiva de recursos desde el centro hacia los municipios permitió a los grupos armados acceder fácilmente al botín econó-

${ }^{40}$ Ibid., p. 375.

${ }^{41}$ NTN24. "Con 41 candidatos asesinados, Colombia tendrá elecciones regionales este domingo", 24 de octubre, 2011. En http://www.ntn24.com/noticias/con-41-candidatos-asesinados-colombia-tendra-elecciones-regionales-est-026655.

${ }^{42}$ Diario El Tiempo, "Hay 978 municipios en riesgo y van 28 candidatos asesinados", 16 de agosto, 2011. En http://www.eltiempo.com/archivo/documento/CMS-10163186. 
mico del Estado para alimentar su economía de guerra. Se puede afirmar, entonces, que el proceso de descentralización, en el caso específico de Colombia, ha sido un claro ejemplo de la forma en que las tendencias y las presiones globales sobre la reconfiguración del Estado nación abrieron nuevas oportunidades económicas y políticas para el reforzamiento de la dinámica del conflicto en el contexto de lo nacional y lo local.

\section{LA TRANSFORMACIÓN DEL CONFLICTO A PARTIR DE LA ECONOMÍA ILÍCITA} DEL NARCOTRÁFICO Y SUS VÍNCULOS CON EL CONTEXTO GLOBAL

Una de las transformaciones más evidentes que el conflicto colombiano ha experimentado, en las dos últimas décadas, es relacionada con el papel desempeñado por el negocio ilegal del narcotráfico como activador de la guerra. Como es bien conocido, en la década de los noventa Colombia se había convertido en el primer productor de cocaína en el nivel mundial, lo cual, en un contexto de marcada ausencia del Estado y de crisis socioeconómica en los escenarios rurales del país, terminó por producir un vínculo negativo entre los actores armados y esta nueva fuente inagotable de recursos económicos.

La potencialidad de esta dinámica se debió en buena parte a que en el nuevo contexto de globalización las nuevas tecnologías de la comunicación, la información y el transporte facilitaron la transnacionalización de las actividades ilícitas a gran escala, brindando un escenario ideal para el establecimiento de redes transnacionales que permitiera vincular de manera más rápida y efectiva a los distintos grupos, mafias e individuos que buscaban maximizar sus ganancias a partir de la alta rentabilidad de los negocios ilícitos. A su vez, la rentabilidad de las actividades criminales en el nivel transnacional se veía fortalecida por la emergencia de una serie de leyes y aparatos de seguridad instaurados por los países potencia, que buscaban erradicar las actividades del mercado consideradas como indeseables. ${ }^{43}$

43 Ethan Nadelmann, "Global Prohibition Regimes: The Evolution of Norms in International Society", en International Organization, vol. 44, núm. 4, 1990, pp. 479-526. 
En el caso de Colombia, vale la pena anotar, además, que ya existía previamente un contexto favorable en el cual las economías del contrabando, las rutas del tráfico de la marihuana y la explotación de esmeraldas como prácticas ilegales fueron abriendo paso a un contexto social e institucional, en que la economía de la droga y sus métodos violentos se fueron integrando y aceptando de manera transitoria en la estructura de la sociedad. ${ }^{44}$

Para la década de los noventa, el vuelco de la economía colombiana hacia el sector exportador terminó por beneficiar a la industria del narcotráfico, en tanto la dimensión de la economía portuaria en Colombia se constituyó en un mecanismo de vital importancia para su inserción económica en el contexto internacional. ${ }^{45}$ No fue entonces una casualidad que las rutas de tráfico de drogas hacia el exterior coincidieran con las salidas de los puertos marítimos ${ }^{46}$ colombianos, y que utilizaran los mismos medios de transporte que son empleados para la comercialización de bienes legales.

De allí resulta obvio, por ejemplo, que un puerto como el de Cartagena, estratégicamente ubicado en el mar Caribe frente a los mercados internacionales y que, además, está impulsando un crecimiento asociado al tráfico de contenedores (transbordo), ${ }^{47}$ en una zona de alta competencia con otros puertos del Ca-

${ }^{44}$ Andrés López, "Narcotráfico, ilegalidad y conflicto en Colombia", en Gutiérrez, Wills y Sánchez, op. cit., p. 409.

45 El país cuenta con cerca de 150 puertos en sus dos litorales, divididos en nueve zonas portuarias y un $85 \%$ del comercio colombiano se ha realizado en las últimas décadas por vía marítima; así mismo, mientras en 2004 el tráfico comercial marítimo tuvo un crecimiento de 3.7\% anual en el ámbito internacional, en Colombia tuvo un crecimiento de 9\%. Joaquín Viloria, "Ciudades portuarias del Caribe colombiano: propuestas para competir en una economía globalizada", en Documentos de trabajo sobre economía regional, núm. 80, Cartagena, Banco de la República, 2006.

${ }^{46}$ La mayor parte de la cocaína que circula en el mundo se transporta por vía marítima.

${ }^{47}$ Cartagena es el puerto colombiano de mayor movimiento de contenedores, ubicado en el puesto 13 entre los principales 24 puertos de la región. Según el autor Peter Andreas, la "containerización" - o el empaque de bienes en containers estandarizados es uno de los mecanismos que han incrementado de manera significativa la eficiencia del transporte, tanto legal como ilegal en el contexto de la economía global. Los containers sellados son muy difíciles de inspeccionar y su volumen total hace que el trabajo del inspector sea casi imposible, por lo que la industria ilegal del narcotráfico se ve altamente beneficiada. Peter Andreas, "Transnational 
ribe y Centroamérica (Panamá, Bahamas y Jamaica principalmente), ${ }^{48}$ se constituyera en uno de los puertos principales para la salida de drogas del país. Asimismo, alrededor de los puertos de Buenaventura y Tumaco en el Pacífico colombiano, que se han convertido en los puertos de mayor movimiento en el ámbito nacional - siendo el puerto de Buenaventura el puerto multipropósito más grande del país-, se registraron entre 2002 y 2007 las más altas cifras de incautaciones de drogas en el nivel nacional. ${ }^{49}$ Igualmente, presenta las más altas cifras de violencia y criminalidad. Esto coincide con la tendencia hemisférica del tráfico de drogas en los últimos diez años, donde los corredores centroamericano y Pacífico ocupan un papel central, especialmente, en el tráfico de la cocaína que se produce en Colombia y que tiene como destino el mercado norteamericano. ${ }^{50}$

Por otra parte, es posible establecer también una relación directa entre las políticas de apertura que tuvieron lugar en Colombia en la década de los noventa y el incremento de la industria de la droga, a partir de ciertos cambios que fueron analizados por el autor Francisco Thoumi, ${ }^{51}$ entre los cuales se encuentran la eliminación de los controles de intercambio, que permitieron a los colombianos tener cuentas financieras y hacer préstamos en el exterior, la declinación en las tarifas de importación y la eliminación de cuotas de la mayoría de las licencias de importación y la promoción de la inversión extranjera directa, que entre otros factores contribuyeron a la expansión de la industria de la droga. En este sentido, el autor se refiere a un estudio de la Drug Enforcement

Crime and Economic Globalization”, en Mats Berdal y Mónica Serrano [eds.], Transnational Organized Crime \& International SecurityBusiness as usual?, United States, Lynne Rienner Publishers. Inc, 2002, p. 41.

48 Departamento Nacional de Planeación, Plan de expansión portuaria 2005-2006: estrategias para la competitividad del sector portuario, Bogotá, Documento Conpes, núm. 3342, 14 de marzo, 2005.

49 United Nations Office on Drugs and Crime, Censo de cultivos de coca, junio de 2008. En http://www.biesimci.org/Documentos/archivos/Censo_Cultivos_Coca_2007_SIMCI.pdf.

${ }^{50}$ United Nations Publications, Informe mundial sobre las drogas, $\overline{2007}$. En http://www. cinu.org.mx/prensa/especiales/2007/informe_drogas/informe_drogas.htm.

51 Francisco Thoumi, Illegal drugs economy and society in the Andes, Washington D.C., Woodrow Wilson Center Press, 2003. 
Administration $^{52}$ que evidencia las dificultades cada vez mayores que este organismo ha tenido para monitorear y controlar la industria ilegal en Colombia debido a que 1. La eliminación de los controles de intercambio hicieron más fácil traer al país grandes sumas de dineros de la droga disfrazados de inversión extranjera de capitales; 2. La privatización de los bancos públicos nacionales permitió a los señores de la droga comprar esos bancos y desarrollar una infraestructura legítima a través de la cual esconder y lavar el capital; y 3. La ausencia de leyes restrictivas para el lavado de dinero en Colombia ha hecho que sea más fácil para que los dineros de la droga entren y penetren en la economía nacional. ${ }^{53}$

Para el momento de la expansión del negocio de la coca en Colombia, en pleno contexto de apertura, los distintos actores armados y delincuenciales se vieron, entonces, enfrentados al aprovechamiento del nuevo contexto externo que brindaba nuevas y masivas fuentes de financiación. Las FARC, por ejemplo, encontraron un nuevo combustible para su economía de guerra, a través de la imposición de tributos sobre un $80 \%$ de las actividades relacionadas con la producción y exportación de cocaína, llegando a obtener alrededor de US\$140 millones provenientes de esos tributos. ${ }^{54}$

Así, en la década de los noventa, cuando se registra un ascenso en la producción de coca, que pasó de 45 mil hectáreas (has) en 1994 a 163 mil (has) sembradas en el año $2000,{ }^{55}$ las FARC habían experimentado también un creci-

52 DEA-Us Drug enforcement Administration, Colombian Economic Reform: The Impact on Drug Money Laundering within the Colombian Economy, Drug Intelligence Report, DEA, Washington D.C., 1994.

53 Thoumi, op. cit., p. 188.

${ }^{54}$ Según Alfredo Rangel, para el año 2000 los ingresos económicos de las FARC se podían calcular entre los US $\$ 300$ y los US $\$ 375$ millones por año, cifra que comprendía dineros recaudados principalmente del narcotráfico y el secuestro extorsivo entre otras formas de financiación. Alfredo Rangel, Guerra insurgente: conflictos en Malasia, Perú, Filipinas, El Salvador y Colombia, Bogotá, Editorial Intermedio, 2001.

55 Momento a partir del cual el área sembrada de coca empezó a decrecer debido a la implementación de las políticas de fumigación y erradicación forzosa. Véase United Nations Office on Drugs and Crime, Colombia Censo... 
miento sin precedentes, que iba de entre los mil y tres mil hombres en 1980, hasta los 10 mil elementos a inicios de los noventa llegando a su punto más alto en 2002 con 18 mil unidades armadas, según cifras oficiales del gobierno. ${ }^{56} \mathrm{~A}$ finales de la década, cuando se registraban las mayores cifras del crecimiento tanto de los cultivos ilícitos como del grupo armado, las farc habían obtenido a su vez los mayores triunfos militares de su historia. ${ }^{57}$

Por su parte, la situación de los grupos paramilitares en relación con las economías ilícitas resultó ser más vinculante, debido al tipo de estructura organizacional descentralizada que los ha caracterizado y a las dificultades para separar los objetivos políticos respecto de los objetivos criminales y económicos en su acción. Se puede considerar al respecto, que los mercados globales de drogas ilícitas propiciaron el fortalecimiento de los grupos paramilitares, llevándolos a un crecimiento de aproximadamente 14 mil hombres armados en $2002 .{ }^{58}$ Vale la pena resaltar, además, que la expansión de este grupo armado también se ha expresado en su clara orientación hacia la protección y fomento de las inversiones extranjeras y de los proyectos macroeconómicos, que se encuentran vinculados con algunos de los mercados locales que han estado bajo su control..$^{59}$

En cuanto a sus fuentes de financiación y los métodos para esconder sus recursos, se ha podido comprobar un fuerte vínculo del paramilitarismo con los flujos ilegales que operan en el mercado ilícito global,

Un investigador en la embajada de Estados Unidos que ha rastreado por años los esquemas de las finanzas paramilitares, hablando en condición de anónimo, dice que el grupo tiene entre US 200 millones y US 1000 millones en bancos de inversión en Suiza, Italia, Luxemburgo y otros países. Otras sumas no reportadas

56 César García, "Las farc perdieron 6000 hombres en 2 años", en El Heraldo, citado en la web del Ejército Colombiano, 19 de enero, 2005.

57 López, op. cit., p. 428.

${ }^{58}$ Mauricio Romero, "Paramilitares, narcotráfico y contrainsurgencia: una experiencia para no repetir", en Francisco Leal [ed.], En la encrucijada Colombia en el siglo XXI, Bogotá, Norma, 2006, p. 375.

59 Lo anterior ha sido, por ejemplo, evidenciado con el caso del manejo paramilitar del negocio de la palma aceitera. 
están en Colombia [...] y el grupo probablemente esconde activos en forma de hoteles, centros comerciales y otras propiedades bajo su control. ${ }^{60}$

Más recientemente, la evolución del actor paramilitar hacia la formación de las denominadas Bacrim, que surgieron del fallido proceso de desmonte de la estructura paramilitar que fue impulsado por el presidente Álvaro Uribe Vélez desde el año 2003 y que produjo la desmovilización de cerca de 32 mil paramilitares, alentó el surgimiento de nuevos grupos criminales como los denominados "Rastrojos", "Urabeños", "Águilas Negras" y "Paisas", que continúan disputándose las redes del crimen organizado para controlar las rutas de transporte y la comercialización de narcóticos hacia el exterior. Lo anterior ha traído como consecuencia un recrudecimiento del conflicto, pues se considera que estos grupos han perdido cualquier connotación política, para dedicarse a la realización de tareas puramente criminales con un alto porcentaje de presencia en el territorio nacional - cerca del 40\%-, que estaría representado en 30 de los 32 departamentos y en algo más de 406 municipios del país. ${ }^{61}$

Finalmente, desde inicios de la década de 2000, las fuerzas armadas gubernamentales también incrementaron sus recursos para la guerra como resultado de una serie de políticas de seguridad, soportadas en un discurso de carácter globalizado. En los últimos dos decenios la dinámica del conflicto fue integrada a las denominadas "guerras globales" contra el narcotráfico y el terrorismo, a través de las ayudas militares y económicas estadounidenses para la lucha contra el narcotráfico y los actores armados catalogados como terroristas. Estas acciones proveyeron al Estado colombiano de una mayor capacidad de ataque y confrontación.

En el año 1999, cuando comienza a definirse claramente la intervención de Estados Unidos a través del Plan Colombia, la Iniciativa Regional Andina y del

${ }^{60}$ Juan Forero, "Ranchers in Colombia bankroll their own militia", en The New York Times, Nueva York, 8 de agosto, 2001, en Ana María Bejarano y Eduardo Pizarro, "Colombia: el colapso parcial del Estado y la emergencia de los protoestados", en Luis Javier Orjuela [comp.], El Estado en Colombia, Bogotá, Uniandes, 2010, p. 402.

61 "Las Bacrim crecen en todo el país", en Diario El Espectador, 19 de febrero, 2012. En http://www.elespectador.com/impreso/judicial/articulo-327595-bacrim-crecen-todo-el-pais. 
apoyo al Plan Patriota, ${ }^{62}$ ocurre un evidente cambio en la correlación de fuerzas y, por ende, una transformación general de la dinámica del conflicto. A partir de allí se produjeron cambios organizacionales, tecnológicos y expansivos de las fuerzas estatales que le significaron al Estado una recuperación importante de territorios. ${ }^{63}$ Esto se manifestó como sostienen Granada, Restrepo y Vargas de la siguiente manera,

Con el apoyo político del gobierno traducido en un gran esfuerzo fiscal, el renovado apoyo del gobierno estadounidense representado en la continuación del Plan Colombia y como parte de su programa de asistencia militar, las fuerzas estatales siguiendo un plan de modernización y crecimiento predefinido, pasaron de tener 145000 combatientes a finales de la década de los noventa, de los cuales menos de un cuarto eran profesionales, ${ }^{64}$ a 431253 en enero de 2009, cifra con la cual las fuerzas estatales alcanzaron el techo de la expansión de su pie de fuerza. ${ }^{65}$

${ }^{62}$ En términos generales estos tres programas hacen parte de una estrategia hemisférica de Estados Unidos para acabar con el narcotráfico y el terrorismo en Latinoamérica, fundamentalmente en Colombia y los países de la región andina como principales fuentes de amenazas en términos de narcotráfico y terrorismo. El costo del Plan Colombia fue estimado en 7500 millones de dólares y Estados Unidos debía aportar una ayuda de 3500 millones de dólares. Desde el año 2000 hasta la fecha 2005, Estados Unidos ha entregado 2600 millones y la Unión Europea 335.9 millones de euros. Para ayudar a los países andinos, la administración Bush pidió 882 millones de dólares en el año fiscal 2002 para el financiamiento de asuntos internacionales con el fin de establecer instituciones democráticas y ayudar al desarrollo, al igual que para programas contra las drogas ilícitas en los siete países incluidos en la iniciativa: Bolivia, Brasil, Colombia, Ecuador, Panamá, Perú y Venezuela. En 2007, la ayuda de Estados Unidos para Colombia será de 700 millones de dólares y los dineros serían invertidos en el Plan Patriota, la estrategia que busca atacar la retaguardia estratégica de las FARC. Cabe decir, sin embargo, que más de la mitad del porcentaje de las ayudas estadounidenses se destinan a la estrategia militar. Véase D'arcier Faivre y Hortense Florez, Del Plan Colombia al Plan Patriota: impacto del conflicto armado colombiano en el Ecuador, análisis de una estrategia de seguridad subregional, Francia, Escoles Militaires de Saint-cyr coëtquidan, Centre de Recherche des Ecoles (CREC), 2005.

63 Soledad Granada, Jorge Restrepo y Andrés Vargas, "El agotamiento de la política de seguridad: evolución y transformaciones recientes en el conflicto armado colombiano", en Restrepo y Aponte, op. cit.

${ }^{64}$ Thomas Marks, "Colombian Army Adaptation to Farc Insurgency", en Strategic Studies Institute, 2002. En http://www.strategicsstudiesinstitute.army.mil/pdffiles/pub18.pdf (fecha de consulta: 5 de marzo, 2009), p. 10.

65 Ibid., p. 79. 
Las consecuencias de este fortalecimiento del Estado fueron múltiples, pues aunque implicó un retroceso temporal de la avanzada guerrillera, la recuperación parcial de las fuerzas del Estado en el territorio nacional y una mayor provisión de seguridad, otros fenómenos como el desplazamiento forzado, la violencia homicida y delincuencial asociada al conflicto y la victimización de la población civil se siguieron expandiendo, una vez que se pusieron en marcha los mecanismos militares de los que disponía el Estado para continuar con la guerra. De hecho, como sugieren Granada, Restrepo y Vargas la campaña contrainsurgente se vio enfrentada a una situación de estancamiento, manifestada en su incapacidad para la desintegración real de los grupos armados y en la configuración de nuevas formas de violencia que se generaron alrededor del problemático fenómeno neoparamilitar.

\section{Conclusiones}

Cada uno de los aspectos analizados en este artículo tiene un peso relativo que explica, con mayor o menor intensidad, las transformaciones recientes del conflicto en relación con el fenómeno de la globalización. La identificación del peso de estos tópicos no sólo es importante porque nos permite matizar y aportar una perspectiva más compleja en el análisis, sino porque a partir de ella será posible establecer algunas generalizaciones que a futuro nos permitan ir más allá del caso específico de Colombia, para empezar a pensar en una teoría más amplia sobre conflictos y globalización.

En cuanto al aspecto socioeconómico, podemos decir que su grado explicativo sólo es válido si se tiene en cuenta que los cambios de la economía colombiana, a partir del nuevo modelo de desarrollo, se dan en un contexto en el cual el conflicto existía previamente a los cambios producidos por la globalización. En este sentido, los efectos del modelo neoliberal y de la apertura globalizadora no produjeron por sí mismos el conflicto, y no existe de hecho una teoría consolidada que demuestre que en los últimos 30 años, estos cambios 
hayan desembocado necesariamente en conflictos armados de largo alcance en los demás países de América Latina, incluso cuando algunos de los conflictos armados existentes como en los casos de El Salvador, Guatemala y Perú se desactivaron durante esta misma época.

Se puede afirmar, sin embargo, que una vez dado el conflicto y en determinadas condiciones (una confrontación armada histórica, la debilidad y ausencia del Estado en buena parte del territorio nacional, la decisión explícita de los actores armados de expandirse, una inversión extranjera creciente y la apertura indiscriminada de la economía por parte de las élites nacionales para satisfacer los requerimientos neoliberales), el cambio económico producido por la globalización contribuyó con la profundización del conflicto a partir de tres efectos específicos: el primero, un cambio en la orientación productiva del país -el paso de una economía basada en el café y la agricultura a una economía basada en la producción de minerales y recursos energéticos- que facilitó la expansión de los actores armados abriendo nuevas oportunidades de financiación a través de recursos fuertemente vinculados a la economía global. El segundo efecto, un ajuste estructural del Estado que, al descentralizar sus funciones con el objetivo de adecuarse a los requerimientos del modelo neoliberal, trasladó el conflicto a una disputa por el poder local que se manifestó en el uso de la violencia armada para apropiarse de los recursos y bienes públicos ${ }^{66}$ Un tercer efecto, derivado de la crisis rural y del sector agrícola que por el impacto de la apertura, la competencia desleal y la profundización de la concentración de la tierra pudo haber ofrecido un contexto favorable para la generación de una base social vinculada a las acciones y motivaciones de los actores armados.

En cuanto al aspecto del cambio global y la economía ilegal del narcotráfico, se puede afirmar que la nueva economía política de los actores armados, derivada de sus vínculos con el negocio ilícito del narcotráfico, ha tenido un mayor peso a la hora de explicar la agudización y prolongación de la guerra en Colombia. Como fue evidenciado a lo largo de este artículo, lo que verdaderamente permitió la expansión y el crecimiento acelerado de los grupos armados fue el

${ }^{66}$ Sánchez y Chacón, op. cit. 
gran combustible de guerra que se incorporó a partir de la economía de las drogas, lo cual no habría podido explicarse sin considerar al actual contexto de la globalización como el gran motor de esta transformación.

No obstante, existen diversos factores que definen de mejor forma la capacidad de ciertos conflictos armados para vincularse con este sistema de carácter ilegal. En el caso del conflicto en Colombia se evidenció en primer lugar, que en muchos territorios del país ya existía previamente la presencia de los actores armados, allí donde más tarde llegó la abundancia de recursos ilícitos, lo cual implica que los supuestos sobre la depredación económica de los actores armados, como origen y evolución del conflicto, son bastante discutibles en este caso. A lo anterior se suma toda una historia previa de bases sociales de apoyo a los grupos armados, condiciones de pobreza, marginación e inequidad y una ausencia permanente del Estado, que explican de manera más compleja la dinámica del conflicto y del tipo de racionalidad que fue desarrollada por los actores armados en torno al negocio de las drogas ilegales.

Finalmente, y en cuanto al fortalecimiento del actor estatal a través de la implementación de las políticas globales de seguridad, se puede considerar que la injerencia estadounidense en el conflicto ha tenido un peso igualmente relevante al haber modificado la correlación de fuerzas de los actores armados en los últimos diez años. Ello supuso una relativa recuperación del territorio por parte de las fuerzas armadas y un retroceso significativo en la avanzada guerrillera, pero también la expansión del fenómeno paramilitar y de las Bacrim, con el consecuente recrudecimiento de la crisis social y humanitaria en diversas regiones del país. Vale la pena considerar, no obstante, que esta dinámica global no habría tenido un efecto tan definitivo de no haber sido por el papel activo de las élites colombianas, que contribuyó a propiciar e incluso a privilegiar la participación directa de un tercer actor en el desarrollo de la guerra; lo que puede ser explicado, en parte, dada la histórica incapacidad económica y militar del Estado para enfrentar sus propias amenazas internas, así como por el mantenimiento continuo de sus relaciones de dependencia frente a Estados Unidos.

Con este artículo se espera finalmente dejar abiertos nuevos interrogantes relacionados con un reto aún mayor, la búsqueda de una terminación pacífica de 
la confrontación armada: ¿Se está viendo constreñida la resolución del conflicto colombiano por factores que derivan del nuevo orden global? ¿De qué forma se pueden superar dichas limitaciones? ¿Qué aspectos deben ser tenidos en cuenta para pensar en la resolución del conflicto colombiano en un contexto de globalización? La respuesta a estas preguntas depende de la formulación de debates, modelos y metodologías hacia los cuales deben ir dirigidos los esfuerzos futuros en la búsqueda a una resolución pacífica del conflicto.

Recibido: 24 de mayo, 2012.

Aceptado: 4 de julio, 2012.

\section{BiBLIOGRAFÍA}

Agencia Nacional De Hidrocarburos, "Sector colombiano del petróleo y el gas", en Caribbean Round, 2007. En http://www.anh.gov.co/ronda2007.anh.gov. co/internae 8ec.html?id $=91$.

AndREAS, Peter, "Transnational Crime and Economic Globalization", en Mats Berdal y Mónica Serrano [eds.], Transnational Organized Crime \& International SecurityBusiness as usual?, United States, Lynne Rienner Publishers, Inc, 2002.

Asociación Campesina del Valle del Río CimitarRa (ACvc), El neoliberalismo, la cuestión agraria y el conflicto social y armado en Colombia, Ponencia presentada por la Acvc en la Conferencia Internacional "El Otro Davos", Magdalena Medio, 19 de enero, 2001. En http://www.prensarural.org/acvc/ acvc20010119.htm.

Colombia, "Minería en Colombia ¿A qué precio?", en Boletín Informativo, núm 18, noviembre, 2011. En http://www.pbi-colombia.org/fileadmin/user_ files/projects /colombia/files/colomPBIa/111122_boletin_final_web.pdf. 
Democracia en la RED, Resistiendo al despojo de la locomotora minero energética, 15 de abril, 2012. En http://democraciaenlared.wordpress.com/ 2012/04/15/resistiendo-al-despojo-de-la-locomotora-minero-energetica/.

Departamento Nacional de Planeación, Plan de expansión portuaria 2005-2006: estrategias para la competitividad del sector portuario, Bogotá, Documento Conpes, núm. 3342, 14 de marzo, 2005.

Diario El ESPECTADOR, "Las Bacrim crecen en todo el país", 19 de febrero, 2012. En http://www.elespectador.com/impreso/judicial/articulo-327595-bacrimcrecen-todo-el-pais.

Diario El TIEMPO, "Hay 978 municipios en riesgo y van 28 candidatos asesinados", 16 de agosto, 2011. En http://www.eltiempo.com/archivo/documento/cms-10163186.

Drug Enforcement Administration (DeA-us), Colombian Economic Reform: The Impact on Drug Money Laundering within the Colombian Economy, Washington D.C., Drug Intelligence Report-DEA, 1994.

ECHeverRI, Juan José, "Colombia en la década de los noventa, neoliberalismo y reformas estructurales en el trópico", en Cuadernos de Economía, vol. 30, núm. 3, 2000, pp. 121-148.

FAzıo, Hugo, "La globalización", en Revista La Tadeo, núm. 70, Bogotá, julio-diciembre, 2004.

2002.

FaIvre, D'ArCier y Hortense Florez, Del Plan Colombia al Plan Patriota: impacto del conflicto armado colombiano en el Ecuador, análisis de una estrategia de seguridad subregional, Francia, Escoles Militaires de Saint-cyr coëtquidan-Centre de Recherche des Ecoles (CREC), 2005.

Fedepalma, The faces of the oil palm, Bogotá, octubre, 2007.

Fedesarrollo, La minería en Colombia: impacto socioeconómico y fiscal, Bogotá, abril de 2008.

Forero, JuAn, "Ranchers in Colombia bankroll their own militia", en The New York Times, Nueva York, 8 de agosto, 2001. Citado en Ana María Bejarano y Eduardo Pizarro, "Colombia: el colapso parcial del Estado y la emergencia de 
los protoestados", en Luis Javier Orjuela [comp.], El Estado en Colombia, Bogotá, Uniandes, 2010.

Galindo, Héctor, Jorge Restrepo y Fabio Sánchez, "Conflicto y pobreza en Colombia: un enfoque institucionalista", en Jorge Restrepo y David Aponte [eds.], Guerra y violencias en Colombia. Herramientas e interpretaciones, Bogotá, Pontificia Universidad Javeriana/CEREC, 2009.

GarCÍA, CÉSAR, "Las Farc Perdieron 6.000 hombres en 2 años", en El Heraldo, citado en la web del Ejército Colombiano, 19 de enero, 2005.

GRANADA, SolEDAD, Jorge Restrepo y Andrés Vargas, "El agotamiento de la política de seguridad: evolución y transformaciones recientes en el conflicto armado colombiano", en Jorge Restrepo y David Aponte [eds.], Guerra y violencias en Colombia. Herramientas e interpretaciones, Bogotá, Pontificia Universidad Javeriana/CEREC, 2009.

Hurtado Mónica y Giovanni Hernández, "Perfil local y agroindustria palmera: explorando el caso de San Alberto y San Martín (Cesar)", en Cuadernos de Desarrollo Rural, vol. 7, núm. 65, Colombia, 2009.

Huntington, SAmuel, La tercera ola: la democratización a finales del siglo, Buenos Aires, Paidós, 1994.

InSTITUTO WORLDWATCH, Informe Vital Sign, 2005. En http://www.worldwatch.org/ bookstore/publication/vital-signs-2005.

Leiteriz, Ralf, Carlo Nasi y Angelika Rettberg, "Para desvincular los recursos naturales del conflicto armado en Colombia", en Revista Colombia Internacional, núm. 70, julio-diciembre, 2009.

LÓPEZ, ANDRÉS, "Narcotráfico, ilegalidad y conflicto en Colombia", en Francisco Gutiérrez, María Emma Wills y Gonzalo Sánchez [coords.], Nuestra guerra sin nombre. Transformaciones del conflicto en Colombia, Bogotá, Instituto de Estudios Políticos y Relaciones Internacionales (IEPRI)/Norma, 2006. Mantilla Valbuena, Silvia, "Hacia una perspectiva "global" del conflicto armado en Colombia: dinámicas y actores en los espacios transfronterizos y transnacionales", en Papel Político, vol. 14, núm. 2, julio-diciembre, 2009. 
"Narcotráfico, violencia y crisis social en el Caribe insular colombiano: el caso de la isla de San Andrés en el contexto del Gran Caribe", en Estudios Políticos, núm. 38, enero-junio, 2011, Medellín-Colombia.

Marks, Thomas, "Colombian Army Adaptation to farc Insurgency, en Strategic Studies Institute, 2002. En http://www.strategicsstudiesinstitute.army.mil/ pdffiles/pub18.pdf (fecha de consulta: 5 de marzo, 2009).

Nadelmann, Ethan, "Global Prohibition Regimes: The Evolution of Norms in International Society”, en International Organization, vol. 44, núm. 4, 1990, pp. 479-526.

NTN24, "Con 41 candidatos asesinados, Colombia tendrá elecciones regionales este domingo", 24 de octubre, 2011. En http://www.ntn24.com/noticias/con41-candidatos-asesinados-colombia-tendra-elecciones-regionales-est-026655.

OcAmpo, Sebastián, "Agroindustria y conflicto armado. El caso de la palma de aceite", en Revista Colombia Internacional, núm. 70, julio-diciembre, 2009. Pearce, Jenny, Policy Failure and Petroleum Predation: The Economics of Civil War Debate Viewed 'From the War-Zone'. Government and Opposition, vol. 4, Issue 2, Oxford, Blackwell Publishing, 2005.

PerfetTi, JuAn José, Crisis y pobreza rural en Colombia, Centro Latinoamericano para el Desarrollo Rural/Instituto de Estudios Peruanos, núm. 43, noviembre, 2009. En http://www.rimisp.org/FCKeditor/UserFiles/File/documentos/docs/ pdf/DTR/N43_2009_Perfetti_crisis-pobreza-rural-caso-Colombia.pdf.

RANGel, Alfredo, Guerra insurgente: conflictos en Malasia, Perú, Filipinas, El Salvador y Colombia, Bogotá, Intermedio, 2001.

Revista Semana, "Colombia produjo 965.000 barriles diario petróleo en noviembre", $1^{\circ}$ de diciembre, 2001. En http://www.semana.com/economia/colombia-produjo-965000-barriles-diario-petroleo-noviembre/168462-3.aspx.

Revista Semana, ¿En dónde está el Petróleo?, 23 de junio, 2012. En http://www.semana.com/economia/donde-esta-petroleo/179414-3.aspx.

Reyes, ALejaNdRo, "La cuestión agraria en la guerra y la paz", en Álvaro Camacho y Francisco Leal [comps.], Armar la paz es desarmar la guerra, Bogotá, CEREC, DNO, FESCOL, IEPRI/Misión Social, Presidencia de la República, 2000. 
Robledo, Jorge EnRique, Neoliberalismo y desastre agropecuario. Ponencia presentada en el Foro "El impacto de la apertura en el sector agropecuario" organizado por la Asociación Nacional por la Salvación Agropecuaria, Ibagué, 8 de junio, 1999.

Romero, Mauricio, "Paramilitares, narcotráfico y contrainsurgencia: una experiencia para no repetir", en Francisco Leal [ed.], En la encrucijada Colombia en el siglo XXI, Bogotá, Norma, 2006.

Rodríguez, Janet, "Petróleo para Dummies", en Carta Petrolera, ed. 118, Bogotá, febrero, 2008. En http://www.ecopetrol.com.co/especiales/cartapetrolera118/rev_empresa. htm.

Sánchez Fabio y Mario Chacón, "Conflicto, Estado y descentralización: del progreso social a la disputa armada por el control local 1974-2002", en Francisco Gutiérrez, María Emma Wills y Gonzalo Sánchez [coords.], Nuestra guerra sin nombre. Transformaciones del conflicto en Colombia, Bogotá, Instituto de Estudios Políticos y Relaciones Internacionales (IEPRI)/Norma, 2006.

TOBASURA, IsAías, "La crisis cafetera, una oportunidad para el cambio en las regiones cafeteras de Colombia”, en Revista Agronomía, vol. 13, núm. 2, Bogotá, julio-diciembre, 2005.

Toffler Alvin, La tercera ola, Barcelona, Plaza y Janés, 1980.

Thoumi, Francisco, Illegal drugs economy and society in the Andes, Washington, D. C., Woodrow Wilson Center Press, 2003.

United Nations Office on Drugs and Crime, Censo de cultivos de coca, junio de 2008. En http://www.biesimci.org/Documentos/archivos/Censo_Cultivos Coca_2007_SIM CI.pdf.

United Nations Office on Drugs and Crime, Colombia Censo de Cultivos de coca, junio, 2005. En http://www.unodc.org/pdf/andean/Colombia_coca_survey_es.pdf.

United Nations Publications, Informe mundial sobre las drogas, 2007. En http://www.cinu.org.mx/prensa/especiales/2007/informe_drogas/informe_drogas.htm. 
VILORIA, JOAQuín, "Ciudades portuarias del Caribe colombiano: propuestas para competir en una economía globalizada", en Documentos de trabajo sobre economía regional, núm. 80, Cartagena, Banco de la República, 2006.

VergaRa, OtTo, "Conflicto y ordenamiento territorial en regiones con potencial minero en Colombia", en Dimensiones territoriales de la guerra y la paz, Bogotá, Universidad Nacional de Colombia, 2004 (Red de Estudios de Espacio y Territorio).

WiLlem Assies, La descentralización en perspectiva, El Colegio de Michoacán y Centro de Estudios Rurales, México, 2003. En http://solidonorte.com/files/ el_arte_de_gobernar/ASSIES\%20Descentralizacion\%20en\%20perspectiva.pdf. 